\title{
Prevalence and renal pathology of pathogenic Leptospira spp. in wildlife in Abeokuta, Ogun State, Nigeria
}

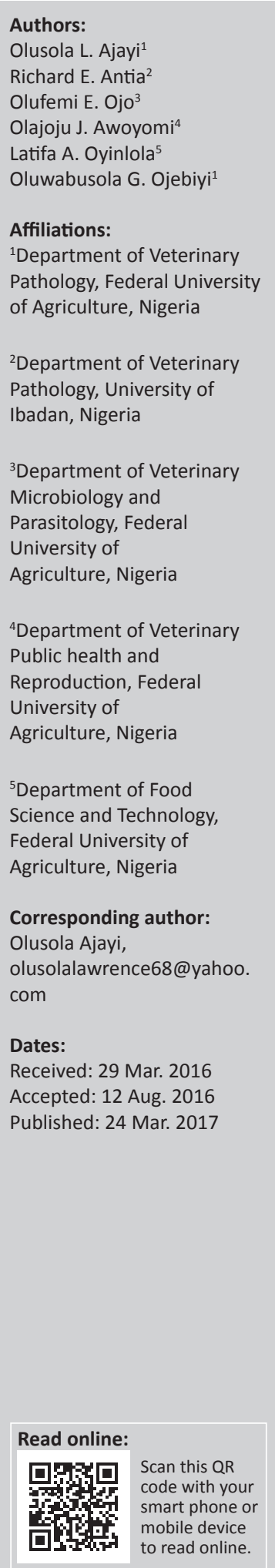

There is paucity of information on the prevalence of leptospirosis in wildlife in Nigeria. This study investigated the prevalence and renal pathology of leptospirosis in wild animals in Southwest Nigeria. One hundred and five kidney samples were examined from 10 different wildlife species (antelope) greater cane rat (GCR), hare, African giant rat (AGR), tree hyrax, civet cat, monitor lizard, python, bushbuck and partridge) using a combination of Ellinghausen McCullough Johnson Harris (EMJH) medium, microscopic agglutination test (MAT), WarthinStarry silver stain (WSss) and immunohistochemistry. Chi-square test was used with confidence level set at 0.05 to ascertain associations between positive cases and sex and species. Eightytwo $(78.1 \%)$ samples were culturally positive, while $67.7 \%(63 / 93), 57.0 \%(16 / 28)$ and $66.7 \%$ $(8 / 12)$ were WSss, MAT and immunohistochemically positive, respectively. Interstitial nephritis $(41.0 \%)$ and tubular nephrosis $(81.0 \%)$ were the most prominent histopathological changes. Pathogenic Leptospira organisms were highest in GCR (32.1\%) and antelope (14.3\%). Serovars hardjo (11.54\%), bratislava $(3.9 \%)$, canicola $(3.9 \%)$, icterohaemorrhagiae $(15.4 \%)$, pomona $(7.14 \%)$ gripptotyphosa $(19.2 \%)$ and undetermined isolates were also detected in other animals. The result showed high prevalence of Leptospira infection in the wild and the possibility of domestic animals and humans contracting the disease. This study is the first documentation of evidence of pathogenic Leptospira species in wildlife in Nigeria.

\section{Introduction}

Leptospirosis has been adjudged the most common and widespread zoonotic disease in the world (World Health Organization 1999). Over the years, wildlife has been increasingly recognised as the reservoir host and environmental disseminator of different pathogenic leptospires (Chin 2000; Cirone et al. 1978; Cox, Smythe \& Leung 2005; Hamir et al. 2001). Increase in disease incidence in domestic animals (especially dogs) and change in serovars involved have been attributed to the endemicity of the disease in wildlife and increase in number of urban wildlife (Okewole \& Ayoola 2009; Prescott et al. 2002).

In Nigeria, leptospirosis has been demonstrated serologically in cattle, sheep and goats (Agunloye 2002; Diallo \& Dennis 1982; Ezeh et al. 1990) with only one case report of a butcher in which serovar hardjoprajitno was isolated from his urine (Ezeh et al. 1991). In dogs appropriately vaccinated with vaccine containing canicola and icterohaemorrhagiae, serological evidence indicated that there is emergence of new serovars of leptospirosis in Southwest Zone of Nigeria (Okewole \& Ayoola 2009).

Despite the zoonotic implication of leptospirosis, little is known of the epidemiology and the health risks of the disease in developing countries, especially in Nigeria where game are regarded as a source of protein. This might be because of lack of awareness and the difficulty associated with the disease recognition and diagnosis.

Current diagnostic methods for leptospirosis in wildlife mostly depend upon demonstration of serum antibodies (Boqvist, Bergstrom \& Magnusson 2012; Montagnaro et al. 2010) and a few instances of cultural isolation (CI) (Felt et al. 2011). In the USA, Canada, Trinidad and Tobago, serology, CI and silver impregnation of renal tissues have been used to determine the prevalence of the disease in the wild (Adesiyun et al. 2006; Alton et al. 2009; Everard et al. 1983;

How to cite this article: Ajayi, O.L., Antia, R.E., Ojo, O.E., Awoyomi, O.J., Oyinlola, L.A. \& Ojebiyi, O.G., 2017, 'Prevalence and renal pathology of pathogenic Leptospira spp. in wildlife in Abeokuta, Ogun State, Nigeria', Onderstepoort Journal of Veterinary Research 84(1), a1210. https://doi.org/10.4102/ojvr.v84i1.1210

Copyright: @ 2017. The Authors. Licensee: AOSIS. This work is licensed under the Creative Commons Attribution License. 
Twigg \& Cox 1976). The most commonly used serological test is the microscopic agglutination test (MAT). Despite the sensitivity of MAT, it is difficult, labour intensive and sometimes the interpretation of the results is confusing and the test does not indicate active infection (Wild et al. 2002). Immunohistochemistry ( $\mathrm{IH}$ ) has been used in recent times to detect Leptospira antigens in the tissues of infected dogs and pinniped populations (Cameron et al. 2008; Ross et al. 2011; Wild et al. 2002). And more recently, IH and polymerase chain reaction were employed as Leptospira diagnostic tools in wildlife in Ontario, Canada (Shearer et al. 2014). Presently, studies on the prevalence and renal pathology of leptospirosis in wildlife using the combination of CI, MAT, Warthin-Starry silver stain (WSss) and IH are few in the literature.

Therefore, the paucity of information on leptospirosis in wildlife in Nigeria and the possibility of people contracting the disease through improperly roasted game inspired us to investigate the prevalence of Leptospira organism in wildlife, isolate and characterise the prevalent serovars, and examine the renal pathological changes associated with the disease using the combination of CI, MAT, WSss and IH.

\section{Materials and methods Study location}

The study was carried out in Abeokuta (the state capital of Ogun State, Nigeria) and its environs (Figure 1). The city of Abeokuta is located in the southwestern part of Nigeria. Its geographical coordinates are latitude $7^{\circ} 15^{\prime} \mathrm{N}$ and longitude $3^{\circ} 35^{\prime} \mathrm{E}$. The average daytime temperature is relatively high,

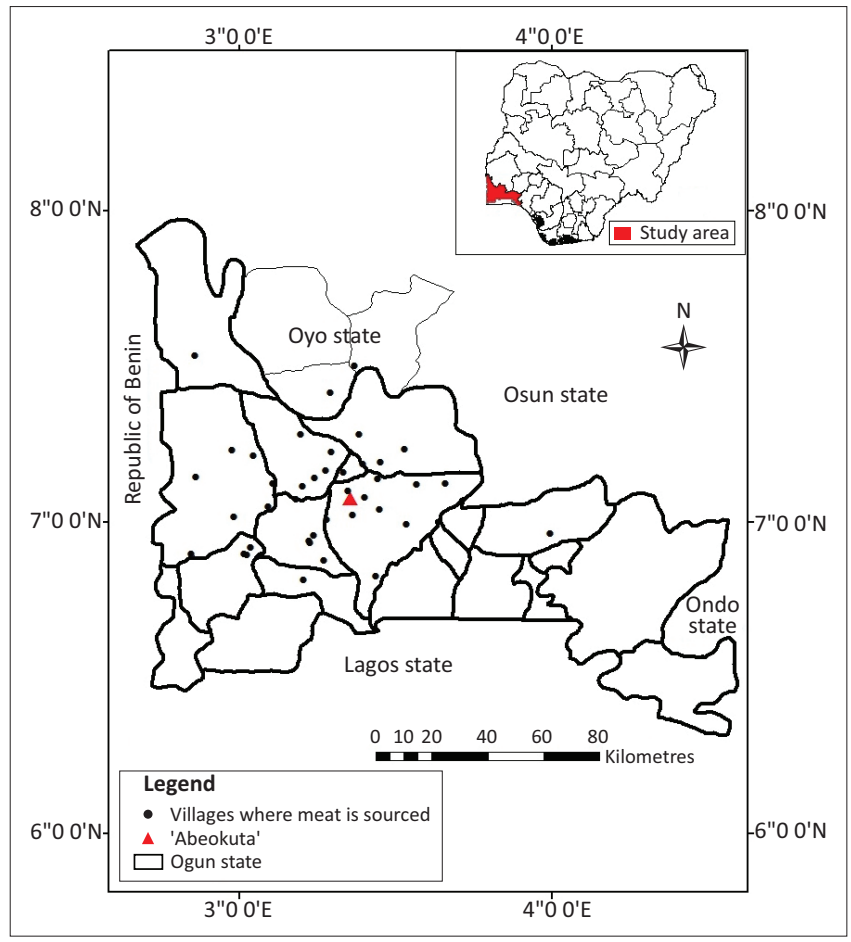

FIGURE 1: A map of Nigeria showing Abeokuta, Ogun State and the local villages and towns where games are sourced with its neighbouring states and the Republic of Benin. generally above $28^{\circ} \mathrm{C}$, with an annual rainfall of $750 \mathrm{~mm}$ and average relative humidity of $74 \%$. The city is about $81 \mathrm{~km}$ southwest of Ibadan, the capital of Oyo State, and $106 \mathrm{~km}$ north of Lagos, the former capital city of Nigeria. The state shares a boundary on the western part with the Republic of Benin. Abeokuta lies at an altitude of about $157 \mathrm{~m}$ a.s.l. (Adekunle \& Agbaje 2011).

\section{Data source}

Data were obtained from the wildlife butchers at the Brewery area of Lafenwa, Abeokuta, Ogun State, where hunters from different parts of the state gather to dress and sell their game. The samples were collected between October 2012 and January 2013. People from different part of the state, neighbouring states (especially Lagos, Oyo, Ondo and Osun states) and different parts of the world usually come to buy fresh game for pepper soup, roasted meat (locally called 'suya') and smoked meat.

\section{Sample identification and collection}

Ten different species of wildlife were examined and identified by the Department of Wildlife Medicine, Federal University of Agriculture Abeokuta. One hundred and five kidney samples (105) were collected from the 10 different species of wildlife with unknown history, which had been trapped and brought for sale by the wildlife hunters. Twenty-two samples were collected from antelope (Philantomba walteri), 54 from greater cane rat (GCR) (Thyronomys swinderianus), 11 from hare (Lepus microtis), 5 from African giant rat (AGR) (Cricetomys gambianus), 3 from tree hyrax (Dendrohyrax dorsalis), 3 from civet cat (Civettictis civetta), 2 from monitor lizard (Varanus niloticus), 3 from python (Python regius), and 1 from both bushbuck (Tragelaphus scriptus) and partridge (Perdix perdix). The sexes of these animals were identified and documented. Visual estimation of their sizes was used to determine their ages, using small, medium and large sizes. The kidneys were collected into ice packs and taken to the Department of Veterinary Pathology, Federal University of Agriculture Abeokuta for subsequent bacteriological and pathological investigations.

\section{Cultural isolation}

\section{Culture medium}

Ellinghausen McCullough Johnson Harris (EMJH) medium (Ellinghausen \& McCullough 1965; Johnson \& Harris 1967) was used for isolation of the Leptospira organisms, modified with the addition of $10 \%$ filtered rabbit's serum $(0.2 \mu \mathrm{m}$ filter $)$. Antibiotics such as chloramphenicol (2 mg/400 mL), nalixidic acid $(20 \mathrm{mg} / 400 \mathrm{~mL})$ and neomycin $(4 \mathrm{mg} / 400 \mathrm{~mL})$ were added and enriched with calcium chloride ( $1 \mathrm{~mL}$ ) and magnesium chloride $(1 \mathrm{~mL})$ as well as the addition of 5-fluorouracil $(400 \mathrm{mg} / \mathrm{L})$ to prevent the growth of other bacteria.

\section{Leptospira isolation}

For each kidney, the renal capsule was removed and a tissue sample was taken using a sterile scalpel blade. Tissues were 
macerated in sterile phosphate buffer solutions (PBS, pH 7.4) using a sterile toothed forceps and then allowed to stay for $10 \mathrm{~min}$. About 5 drops of the tissue extract were inoculated into the medium and incubated at room temperature $\left(28^{\circ} \mathrm{C}-\right.$ $30^{\circ} \mathrm{C}$ ) in the dark. The culture medium was examined after 24 hours for the growth of Leptospira organism and later weekly under dark field microscopy.

\section{Characterisation of Leptospira isolates using microscopic agglutination test}

Twenty-eight uncontaminated isolates were characterised as previously described (Obregón et al. 2007) using six monoclonal antibodies (mAbs) (Table 1). The serogroups of mAbs used include canicola, icterohaemorrhagiae, bratislava, grippotyphosa, pomona and hardjo. A 50\% reduction in the number of free leptospires in the test sample was considered positive with or without agglutination and was recorded as the respective titre (Senthil, Ramadass \& Nachimutu 2001).

\section{Pathological changes}

Samples of the kidney were grossly and histopathologically examined. They were collected into neutral buffered $10 \%$ formalin and processed via standard paraffin-embedding techniques. Sections of the 105 kidney samples were cut at $5 \mu \mathrm{m}$ and stained with haematoxylin and eosin stain, while 93 sections were stained with WSss. Gross and histopathological grading of the observed lesions was performed. The severity of the gross lesions was graded as absent $(-)$, mild $(+)$, moderate $(++)$ and marked $(+++)$. For interstitial nephritis (IN), scores were assigned as follows: $+=1-2$ foci on section examined, $++=3-4$ foci on section examined, $+++=>5$ foci on section examined. The severity or density of Leptospira organism using WSss was determined according to the method of Twigg and Cox (1976) with slight modification using mild (+) for 1-2 foci with low density of the organism forming a thin layer on the apical part of tubular epithelial cells, moderate (++) for 3-4 foci with denser mass in the form of a thick rope around the lumen with a clear centre and marked $(+++)=>5$ foci with entire lumen occluded by a tangled mass of Leptospira organisms. The severity of tubular colonisation and zonal localisation (cortex, medulla and corticomedullary junction) of Leptospira infection was also determined.

\section{Immunohistochemistry}

Three samples each were selected from four different species, namely antelope, hare, AGR and GCR for IH. The rabbit

TABLE 1: Reference rabbit leptospiral antisera used for characterisation of leptospiral isolates from wildlife.

\begin{tabular}{lll}
\hline Serogroup & Serovar & Strain \\
\hline Canicola & Canicola & Hond Utrecht IV \\
Icterohaemorrhagiae & Icterohaemorrhagiae & RGA \\
Pomona & Pomona & Pomona \\
Grippotyphosa & Grippotyphosa & Moskva V \\
Sejroe & Hardjo type Prajitno & Hardjoprajitno \\
Australis & Bratislava & Jez Bratislava \\
\hline
\end{tabular}

immune sera-cocktail (Table 1) used as primary antibodies against Leptospira antigens in the kidney sections were graciously provided by Prof. R.A. Hartskeerl (WHO/FAO/ OIE and National Leptospirosis Reference Centre, KIT Biomedical Research, Amsterdam, the Netherlands). IH was performed as previously described (Ross et al. 2011). All steps were performed at room temperature. The sections were first incubated in 3\% hydrogen peroxide for $15 \mathrm{~min}$ to quench endogenous peroxide. After a brief wash of TPBS, Histomark (Biotin streptavidin-HRP System, Goat antiRabbit IgG [H+L] KLP, Gaitherburg, USA) detection system was used. Non-specific binding was done by bathing in normal goat serum for $10 \mathrm{~min}$. The tissues were then incubated with specific $\mathrm{mAb}$ (1:800 dilutions in PBS) for $30 \mathrm{~min}$. After a last wash in TPBS, the slides were incubated with streptavidin-biotin-horseradish peroxidase for $15 \mathrm{~min}$. Slides were then rinsed with distilled water and incubated with 3-amino-9-ethylcarbazole-peroxidase chromogen for $10 \mathrm{~min}$, rinsed with distilled water and counterstained with Mayer haematoxylin for $90 \mathrm{~s}$, rinsed and mounted with glycerol for microscopic examination.

\section{Statistical analysis}

Descriptive statistics were used for both positive and negative cases for different levels of age, sex and species. Chi-square test of association was used with confidence level set at 0.05 to ascertain associations between positive cases and sex and species of animals involved.

\section{Results}

The prevalence of Leptospira organism according to sexes and sizes in the wildlife using EMJH medium is depicted in Table 2. Eighty-two (78.10\%) samples were culturally positive for Leptospira infection out of the 105 kidney samples examined. Out of the 22 Antelopes, 18 (81.80\%) were positive and $4(18.20 \%)$ were negative. Twenty-seven $(50.00 \%)$ of the 54 GCRs were positive, while $27(50.00 \%)$ were negative. Of the 11 hare samples examined, 7 (63.64\%) were positive, while $4(36.36 \%)$ were negative. Out of the 5 and 3 samples examined from AGR and tree hyrax, 4 (80.00\%) and 2 (67.00\%) were positive, respectively, and only 1 sample was negative in both species. Two and 3 samples were examined from monitor lizard and python, respectively, with $100 \%$ positivity in each case. One kidney sample each was examined in the bushbuck and partridge and both were positive.

Of the 105 animals, 52 (49.5\%) were males and 53 (50.5\%) were females. Of the 52 male samples, 40 (76.9\%) were positive, while $42(79.3 \%)$ were positive of the 53 female samples. GCR had the highest infection prevalence of $57.5 \%$ compared with $17.5 \%$ and $15 \%$ in antelopes and hare, respectively. Of the 42 positive females, GCR also showed the highest prevalence of $42.9 \%$, while antelope and AGR had $26.2 \%$ and $7.1 \%$, respectively. Other animals such as tree hyrax, monitor lizard, python and civet cat had $4.8 \%$ prevalence each. The hare and partridge showed the least prevalence of $2.4 \%$ each among the positive female animals. 
TABLE 2: The prevalence of Leptospira organisms in 105 kidneys of wildlife in Ellinghausen McCullough Johnson Harris medium according to sex and size.

\begin{tabular}{|c|c|c|c|c|c|c|c|c|c|c|c|c|c|c|c|}
\hline \multirow[t]{3}{*}{ Species } & \multirow[t]{3}{*}{ Total } & \multirow{3}{*}{$\begin{array}{c}\text { Number } \\
\text { tve }\end{array}$} & \multirow[t]{3}{*}{$\%+v e$} & \multirow{3}{*}{$\begin{array}{c}\text { Number } \\
\text {-ve }\end{array}$} & \multirow[t]{3}{*}{$\%$-ve } & \multicolumn{4}{|c|}{ Sex } & \multicolumn{6}{|c|}{ Size } \\
\hline & & & & & & \multicolumn{2}{|c|}{ Male } & \multicolumn{2}{|c|}{ Female } & \multicolumn{2}{|c|}{ Small } & \multicolumn{2}{|c|}{ Medium } & \multicolumn{2}{|c|}{ Large } \\
\hline & & & & & & $+v e / \%$ & - -ve/\% & +ve/\% & -ve/\% & $+\mathrm{ve} / \%$ & - -ve/\% & +ve/\% & -ve/\% & +ve/\% & -ve/\% \\
\hline Antelope & 22 & 18 & 81.80 & 4 & 18.20 & $07 / 17.5$ & $02 / 16.7$ & $11 / 26.2$ & $02 / 18.1$ & - & - & $4.0 / 12.0$ & - & $13 / 46.4$ & $05 / 71.4$ \\
\hline Greater cane rat & 54 & 41 & 50.00 & 13 & 50.00 & $23 / 57.5$ & $09 / 75.0$ & $18 / 42.9$ & $04 / 36.4$ & $08 / 38.0$ & $06 / 66.7$ & $23 / 69.7$ & $06 / 85.7$ & $10 / 35.7$ & $01 / 14.3$ \\
\hline Hare & 11 & 7 & 63.64 & 4 & 36.36 & $06 / 15.0$ & - & $01 / 2.4$ & $04 / 36.4$ & $06 / 28.5$ & $02 / 22.2$ & $02 / 6.1$ & $01 / 14.3$ & - & - \\
\hline African giant rat & 5 & 4 & 80.00 & 1 & 20.00 & $01 / 2.5$ & $01 / 8.3$ & $03 / 7.1$ & - & $04 / 19.1$ & $01 / 11.1$ & - & - & - & - \\
\hline Tree hyrax & 3 & 2 & 66.67 & 1 & 33.33 & - & - & $02 / 4.8$ & $01 / 9.1$ & $01 / 4.8$ & - & - & - & $01 / 3.6$ & $01 / 14.3$ \\
\hline Bushbuck & 1 & 1 & 100.00 & - & - & $01 / 2.5$ & - & - & - & - & - & - & - & $01 / 3.6$ & - \\
\hline Monitor lizard & 2 & 2 & 100.00 & - & - & - & - & $02 / 4.8$ & - & - & - & $02 / 6.1$ & - & - & - \\
\hline Partridge & 1 & 1 & 100.00 & - & - & - & - & $01 / 2.4$ & - & $01 / 4.8$ & - & - & - & - & - \\
\hline Python & 3 & 3 & 100.00 & - & - & $01 / 2.5$ & - & $02 / 4.8$ & - & - & - & - & - & $03 / 10.7$ & - \\
\hline Civet cat & 3 & 3 & 100.00 & - & - & $01 / 2.5$ & - & $02 / 4.8$ & - & $01 / 4.8$ & - & $02 / 6.1$ & - & - & - \\
\hline Total & 105 & 82 & 78.10 & 23 & 21.90 & 40 & 12 & 42 & 11 & 21 & 9 & 33 & 7 & 28 & 7 \\
\hline
\end{tabular}

+ve, positive; -ve, negative; -, absent; \% -ve, percentage negative; \% +ve, percentage positive.

TABLE 3: Prevalence and characterisation of 28 Leptospira isolates of wild animals using monoclonal antibodies in the microscopic agglutination test.

\begin{tabular}{|c|c|c|c|c|c|c|c|c|c|c|c|}
\hline Number & Serovars & $\begin{array}{c}\text { Number } \\
\text { +ve }\end{array}$ & $\begin{array}{c}\text { Prevalence } \\
(\mathbf{\%})\end{array}$ & $\begin{array}{l}\text { Agglutination } \\
\text { titre }\end{array}$ & $\begin{array}{c}\text { Antelope } \\
(n=6)\end{array}$ & $\begin{array}{c}\text { Greater Cane } \\
\text { rat }(n=15)\end{array}$ & $\begin{array}{l}\text { Hare } \dagger \\
(n=2)\end{array}$ & $\begin{array}{l}\text { African giant } \\
\text { rat }(n=1)\end{array}$ & $\begin{array}{c}\begin{array}{c}\text { Bushbuck } \\
(n=1)\end{array} \\
\end{array}$ & $\begin{array}{c}\text { Partridge } \\
(n=1)\end{array}$ & $\begin{array}{l}\text { Python } \\
(n=2)\end{array}$ \\
\hline 1 & Leptospira pomona & 2 & 7.14 & $1 ; 3200$ & 2 & - & - & - & - & - & - \\
\hline 2 & Leptospira grippotyphosa & 5 & 19.23 & $1 ; 3200$ & 1 & 2 & - & 1 & - & - & 1 \\
\hline 4 & Leptospira bratislava & 1 & 3.85 & $1 ; 1600$ & - & 1 & - & - & - & - & - \\
\hline 5 & Leptospira canicola & 1 & 3.85 & $1 ; 800$ & - & 1 & - & - & - & - & - \\
\hline \multirow[t]{2}{*}{6} & Leptospira icterohaemorrhagie & 3 & 15.38 & $1 ; 1600$ & - & 2 & - & - & - & 1 & - \\
\hline & Undetermined isolates & 12 & 42.90 & - & 2 & 6 & 2 & - & 1 & - & 1 \\
\hline
\end{tabular}

+ ve, positive; -, absent; $\uparrow$, contamination and undecided.

There were no significant $(p>0.05)$ sex and species differences in Leptospira prevalence.

Of the 105 kidney samples, 30 animals (28.5\%) were of small size and $40(38.1 \%)$ medium size, while $35(33.4 \%)$ were of large adult size. Of the juvenile small-sized animals, 21 $(70.0 \%)$ were positive; GCR and hare had the highest prevalence of $8(38.0 \%)$ and $6(28.5 \%)$, respectively. Among the medium-sized animals, $33(82.5 \%)$ were positive. Antelope and GCR had the highest prevalence of $4(12.0 \%)$ and 23 $(69.7 \%)$, respectively. Within the 35 large-sized adults, 28 (80.0\%) were culturally positive, with antelope and GCR having the highest prevalence of $46.4 \%$ and $35.7 \%$, respectively.

Table 3 depicts the characterisation and distribution of the Leptospira isolates from different wild animals. Of the 82 cultured isolates, 28 uncontaminated samples were used for MAT. Leptospira grippotyphosa had the highest isolates of 5 $(19.23 \%)$ with agglutination titre of 1:3200. Two of the 5 L. gripptotyphosa isolates were isolated from GCR, while 1 each was isolated from python, antelope and AGR. This was closely followed by Leptospira hardjo with 4 (15.38\%) isolates; 3 (10.70\%) from GCR and 1 from antelope with agglutination titre of 1:1600. There were three $(10.70 \%)$ Leptospira icterohaemorrhagiae isolates from 2 GCRs and 1 partridge with agglutination titre of 1:1600. Leptospira pomona was $2(7.00 \%)$ isolates, isolated from 2 antelopes with agglutination titre of 1:3200. One each of $(4.00 \%)$ Leptospira bratislava and Leptospira canicola was isolated and characterised from two GCRs and showed agglutination titre of 1:1600 and 1:800, respectively.
Of the 105 kidney samples collected, only 24 (22.90\%) showed visible gross lesions. The type, severity and the distribution of the lesions are depicted in Table 4 . The gross changes revealed 2 kidneys with multiple foci of cortical haemorrhages from 1 antelope and 1 monitor lizard, while 8 (6.86\%) animals (2 antelopes, 4 GCRs and 2 AGR) had moderate-to-severe rough and pitted cortical surfaces with adherence of the renal capsule. Mild-to-moderate cortical necrosis in 9 (5.88\%) animals (5 antelopes, 2 GCRs and 1 each from AGR and bushbuck) and $2(1.96 \%)$ moderate multiple foci of pale nodules from antelope and GCR were observed. A moderate locally extensive red infarct was observed in the kidney of 1 tree hyrax and 2 renal hypoplasia from $1 \mathrm{GCR}$ and 1 hare. Of the 24 samples with gross lesions, 18 (75.00\%) were culturally positive, while 64 (70.00\%) from the remaining 81 samples without macroscopic lesions were also positive. Of the 18 culturally positive samples with gross lesions, 7 each were from antelopes and GCRs, while 2 were from AGRs and 1 each from bushbuck and monitor lizard.

Results of histopathological changes, Warthin-Starry silver impregnation and IH of all the kidney sections collected are shown in the Tables 5 and 6. In all cases (both Leptospira positive and negative tissues), there were histopathological alterations in the kidneys. Tubular nephrosis (81.0\%), IN $(41.0 \%)$, interstitial fibrosis $(20.0 \%)$ and protein cast $(25.7 \%)$ were the most prominent histopathological changes observed in the kidney samples of both infected and non-infected animals, but these lesions were more marked in the infected animals. IN was mostly cortical. The IN was characterised by peritubular, perivascular and periglomerular lymphoplasmacytic inflammatory foci, and these coalesced 
TABLE 4: Gross morphologic lesions of the kidney in relation to cultural isolation of Leptospira organisms.

\begin{tabular}{|c|c|c|c|c|c|c|c|c|c|c|}
\hline \multirow[t]{2}{*}{ Species } & \multirow[t]{2}{*}{ Total } & \multirow{2}{*}{$\begin{array}{l}\text { Number } \\
\text { +ve }\end{array}$} & \multicolumn{6}{|c|}{ Gross morphological changes } & \multirow[b]{2}{*}{ CP/PL (\%) } & \multirow[b]{2}{*}{ CP/AL (\%) } \\
\hline & & & $\mathrm{CH}$ & PRCS & RN & MPN & RI & RH & & \\
\hline Antelope & 22 & 18 & $01(+)$ & $02(++)$ & $05(++)$ & $01(+)$ & - & - & $7 / 9(77.8)$ & $11 / 13(84.6)$ \\
\hline Greater cane rat & 54 & 41 & - & $04(+++)$ & $02(+)$ & $01(+)$ & - & $01(++)$ & $7 / 8(87.5)$ & $34 / 46$ (73.9) \\
\hline Hare & 11 & 7 & - & - & - & - & - & $01(+)$ & $0 / 1(-)$ & $07 / 10(70.0)$ \\
\hline African giant rat & 5 & 4 & - & $02(++)$ & $01(+)$ & - & - & - & $2 / 3(66.7)$ & 02/02 (100) \\
\hline Tree hyrax & 3 & 2 & - & - & - & - & $01(++)$ & - & $0 / 1(-)$ & $02 / 02(100)$ \\
\hline Bush buck & 1 & 1 & - & - & $01(+)$ & - & - & - & $1 / 1(100)$ & - \\
\hline Monitor lizard & 2 & 2 & $01(+)$ & - & - & - & - & - & $1 / 1(100)$ & 01/01 (100) \\
\hline Partridge & 1 & 1 & - & - & - & - & - & - & - & 01/01 (100) \\
\hline Python & 3 & 3 & - & - & - & - & - & - & - & 03/03 (100) \\
\hline Civet cat & 3 & 3 & - & - & - & - & - & - & - & 03/03 (100) \\
\hline Total & 102 & 82 & 2 & 8 & 9 & 2 & 1 & 2 & $18 / 24(75)$ & $64 / 81(79.0)$ \\
\hline
\end{tabular}

+ve, number positive; $\mathrm{CH}$, cortical haemorrhages; PRCS, pitted and rough cortical surface; RN, renal nephrosis; MPN, multifocal pale nodules; RI, renal infarct; RH, renal hypoplasia; CP/PL, culturally positive /presence of lesions; CP/AL, culturally positive/absence of lesions, - , absent, +, mild, ++, moderate, +++, marked or severe.

TABLE 5: Renal localisation and tubular colonisation of Leptospira organism in wildlife using Warthin-Starry silver stain.

\begin{tabular}{|c|c|c|c|c|c|c|c|c|c|c|c|c|}
\hline \multirow[t]{2}{*}{ Species } & \multirow{2}{*}{$\begin{array}{c}\text { Total } \\
(n=93)\end{array}$} & \multirow{2}{*}{$\begin{array}{l}\text { Number } \\
\text { +ve }(\%)\end{array}$} & \multirow{2}{*}{$\begin{array}{l}\text { Number } \\
\text {-ve }(\%)\end{array}$} & \multicolumn{3}{|c|}{ Tubular colonisation } & \multicolumn{3}{|c|}{ Zonal localisation } & \multicolumn{3}{|c|}{ Severity of tubular colonisation } \\
\hline & & & & PCT & DCT & $\mathrm{COL}$ & Cort. & CMJun. & Med. & + & ++ & +++ \\
\hline Antelope & 19 & 7 & 12 & 6 & 4 & 2 & 3 & 3 & 1 & 7 & - & - \\
\hline Greater cane rat & 51 & 42 & 9 & 27 & 20 & 13 & 15 & 22 & 5 & 25 & 14 & 3 \\
\hline Hare & 10 & 7 & 3 & 6 & 4 & 1 & 2 & 4 & 1 & 5 & 2 & - \\
\hline African giant rat & 3 & 3 & - & 1 & 1 & 1 & 1 & 1 & 1 & 3 & - & - \\
\hline Tree hyrax & 3 & - & 3 & - & - & - & - & - & - & - & - & - \\
\hline Bush buck & 1 & - & 1 & - & - & - & - & - & - & - & - & - \\
\hline Monitor lizard & 2 & 2 & - & 2 & - & 1 & 2 & - & 1 & 2 & - & - \\
\hline Partridge & 1 & - & 1 & - & - & - & - & - & - & - & - & - \\
\hline Python & 3 & 2 & 1 & 1 & 1 & - & - & 1 & 1 & 1 & 1 & - \\
\hline Total & 93 & $63(67.7 \%)$ & $30(32.3 \%)$ & 43 & 30 & 18 & 23 & 31 & 10 & 43 & 17 & 3 \\
\hline
\end{tabular}

ve, positive; -ve, negative; PCT, proximal convoluted tubules; DCT, distal convoluted tubules; COL, collecting ducts; Cort., cortex; CMJun., corticomedullary junction; Med., medulla; -, absent; +, mild ++ , moderate; +++, marked or severe.

TABLE 6: Summary of the positive samples, histopathological changes, serovars identified and the methodologies used

\begin{tabular}{|c|c|c|c|c|c|c|c|c|c|c|c|c|}
\hline \multirow[t]{2}{*}{ Number } & \multirow[t]{2}{*}{ Species } & \multirow[t]{2}{*}{ Total } & \multirow{2}{*}{$\begin{array}{l}\text { Number } \\
+ \text { +ve }\end{array}$} & \multicolumn{4}{|c|}{ Histopathological changes } & \multicolumn{3}{|c|}{ Severity of IN } & \multirow[t]{2}{*}{ Serovars identified } & \multirow[t]{2}{*}{ Methodologies } \\
\hline & & & & IN & TN & IF & PC & + & ++ & +++ & & \\
\hline 1 & Antelope & 22 & 18 & 10 & 20 & 4 & 10 & 8 & 2 & - & Leptospira grippotyphosa & $\mathrm{Cl}, \mathrm{MAT}, \mathrm{WSss}$ and $\mathrm{IH}$ \\
\hline \multirow[t]{3}{*}{2} & Greater cane rat & 54 & 27 & 24 & 47 & 16 & 12 & 20 & 3 & 1 & $\begin{array}{l}\text { Leptospira hardjo, } \\
\text { Leptospira canicola }\end{array}$ & $\mathrm{Cl}, \mathrm{MAT}, \mathrm{WSss}$ and $\mathrm{IH}$ \\
\hline & & & & & & & & & & & $\begin{array}{l}\text { Leptospira bratislava, } \\
\text { Leptospira } \\
\text { icterohaemorrhagiae }\end{array}$ & \\
\hline & & & & & & & & & & & Leptospira grippotyphosa & \\
\hline \multirow[t]{2}{*}{3} & Hare & 11 & 7 & 6 & 7 & - & 4 & 5 & 2 & - & $\begin{array}{l}\text { Leptospira } \\
\text { icterohaemorrhagiae, } \\
\text { Leptospira canicola }\end{array}$ & $\mathrm{Cl}$ and $\mathrm{IH}$ \\
\hline & & & & & & & & & & & Leptospira bratislava & \\
\hline 4 & African giant rat & 5 & 4 & 1 & 2 & - & - & 1 & - & - & $\begin{array}{l}\text { Leptospira bratislava, } \\
\text { Leptospira grippotyphosa }\end{array}$ & $\mathrm{Cl}, \mathrm{MAT}$ and $\mathrm{IH}$ \\
\hline 5 & Tree hyrax & 3 & 2 & - & 3 & - & - & - & - & - & ND & $\mathrm{Cl}$ \\
\hline 6 & Bush buck & 1 & 1 & - & 1 & - & - & - & - & - & ND & $\mathrm{Cl}$ \\
\hline 8 & Partridge & 1 & 1 & - & 1 & - & - & - & - & - & $\begin{array}{l}\text { Leptospira } \\
\text { icterohaemorrhagiae }\end{array}$ & $\mathrm{Cl}, \mathrm{MAT}$ \\
\hline 9 & Python & 3 & 3 & 1 & 2 & - & - & 1 & - & - & Leptospira grippotyphosa. & $\mathrm{Cl}, \mathrm{MAT}$ \\
\hline 10 & Civet cat & 3 & 3 & - & - & - & - & - & - & - & ND & $\mathrm{Cl}$ \\
\hline Total & - & 105 & 82 & 43 & 85 & 21 & 27 & 35 & 7 & 1 & - & - \\
\hline
\end{tabular}

+ve, positive; IN, interstitial nephritis; TN, tubular nephrosis; IF, interstitial fibrosis; PC, protein cast; -, absent; +, mild; ++, moderate; +++, marked or severe; ND, not determined; Cl, cultural isolation; MAT, microscopic agglutination test; WSss, Warthin-Starry silver stain; IH, immunohistochemistry.

in some sections (Figure 2). The severity of IN was mild in 35 $(81.4 \%)$ animals, moderate in $7(16.3 \%)$ and marked in only 1 (2.3\%). GCR showed the highest prevalence of IN with 24 $(55.8 \%)$ of the 43 wild animals that demonstrated the lesion.

Of the 93 samples examined using WSss, 63 (67.7\%) showed the presence of the organism. The morphological appearance of the organism was either intact or granular and in some cases intertwined, having a light brown to black appearance (Figure 3). Tubular colonisation showed that proximal convoluted tubules (PCT) demonstrated the highest prevalence compared with distal convoluted tubules (DCT) and collecting tubules. Despite the fact that PCT demonstrated the highest tubular colonisation, the corticomedullary 


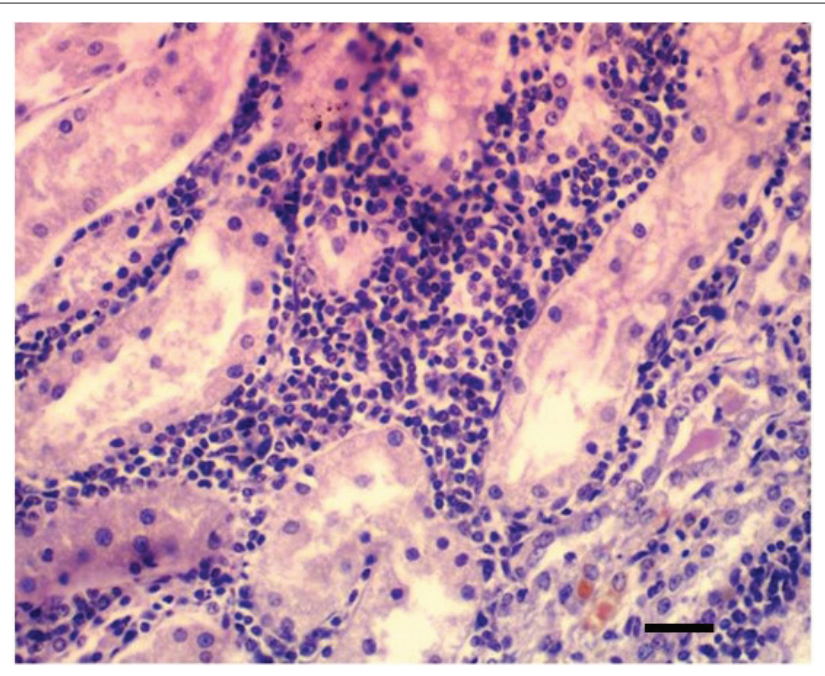

Bar $=80 \mu \mathrm{m} \mathrm{H} \& \mathrm{E}$.

FIGURE 2: Kidney section showing tubular degeneration and necrosis, tubula atrophy with moderate diffuse interstitial lymphoplasmacytic cellular infiltration in antelope positive with Leptospira infection.

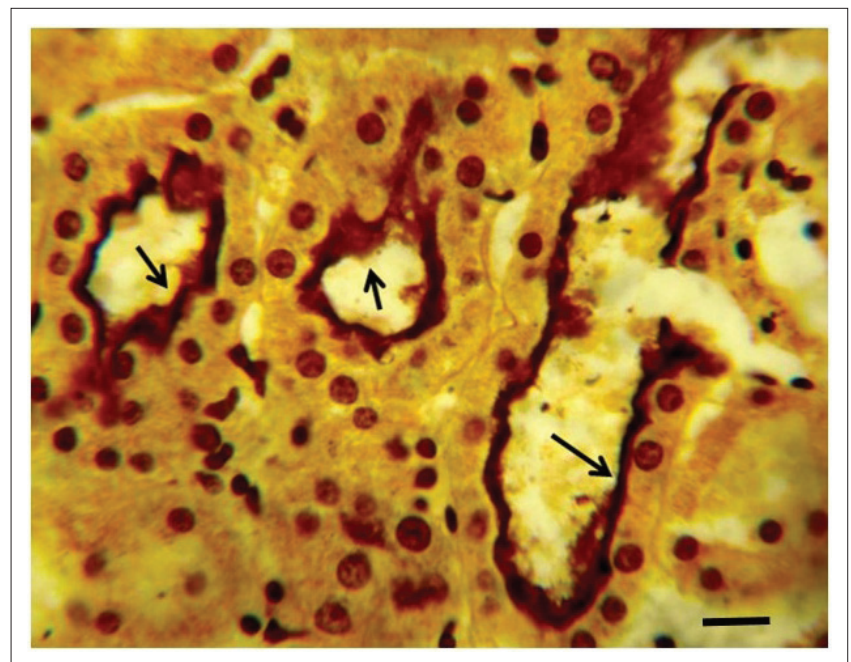

Bar $=50 \mu \mathrm{m}$.

Warthin-Starry silver stain

FIGURE 3: Photomicrograph of severely colonised proximal convoluted tubules and absence of interstitial mononuclear cells infiltration in the interstitium.

junction showed the highest zonal localisation compared with the cortical and medullary zones. The severity of the tubular colonisation showed that the infection was mild in $43(68.0 \%)$ kidneys, while it was moderate in $17(27.0 \%)$ samples and severe in only $3(5.0 \%)$ kidney samples.

IH of Leptospira antigens in the three kidney samples of hare were all positive with three different serovars detected (L. icterohaemorrhagiae, L. canicola, L. bratislava) (Figure 4). Two of the three samples in antelope were positive for $L$. hardjo (Figure 5), while L. bratislava and L. gripptotyphosa were detected in AGR. Only one of the three samples was positive in GCR for L. gripptotyphosa.

In summary, five different Leptospira serovars were isolated, characterised and detected from GCR using CI, MAT and IH. Three serovars each from antelope (L. hardjo, L. pomona and

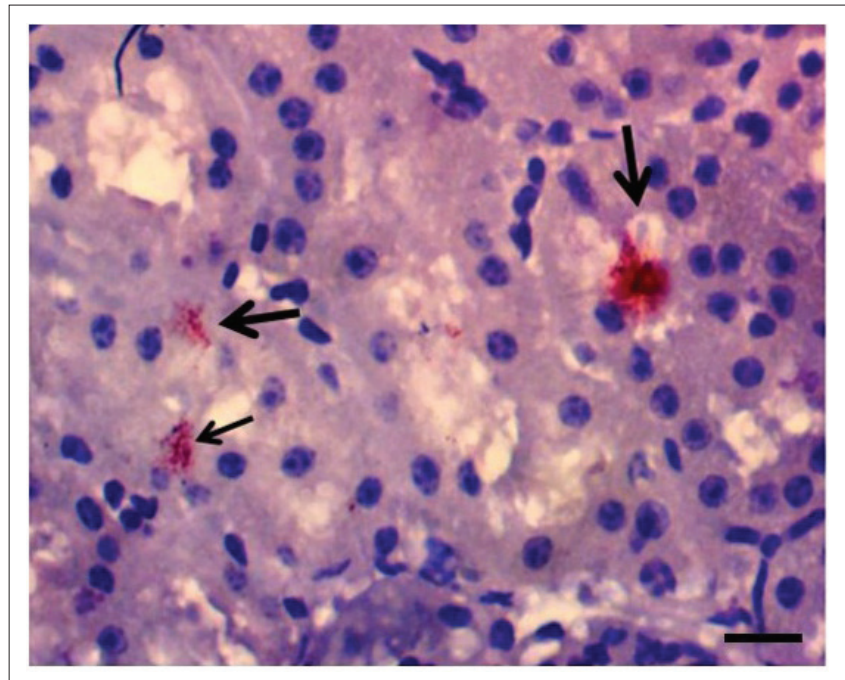

Bar $=50 \mu \mathrm{m}$ Streptavidin-biotin peroxidase method, counterstained with Mayer's heamatoxylin.

FIGURE 4: Kidney section of antelope showing immunoreactivity of Leptospira interrogans serovar hardjo antigen in the tubular lumen (arrows).

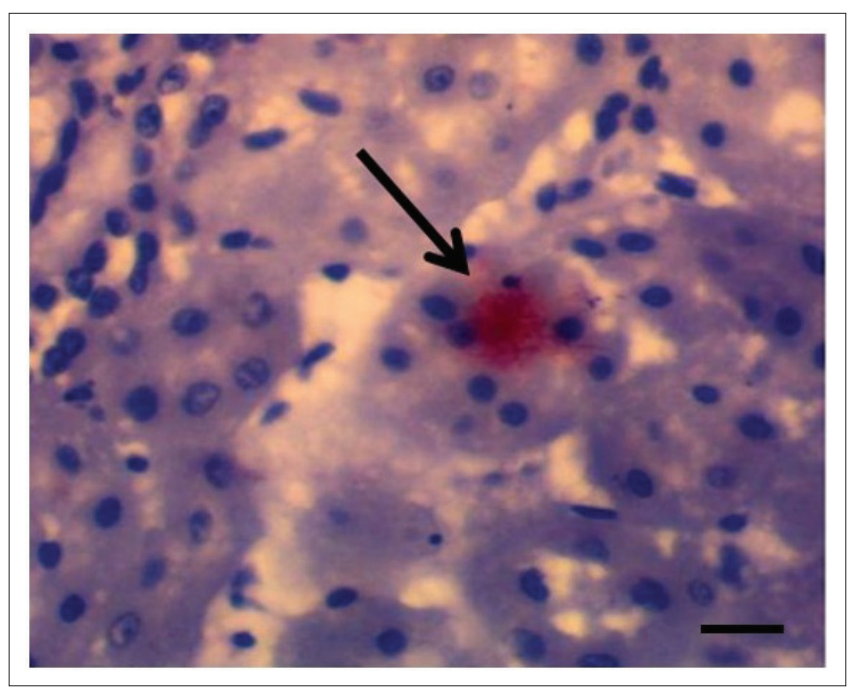

Bar $=50 \mu \mathrm{m}$ Streptavidin-biotin peroxidase method, counterstained with Mayer's heamatoxylin.

FIGURE 5: Kidney section of Hare showing strong immunoreactivity to Leptospira interrogans serovar bratislava antigen in the lumen of distal convoluted tubule (arrow).

L. gripptotyphosa) and hare (L. canicola, L. icterohaemorrhagiae, L. bratislava) were detected, while two were detected from AGR and one each from python and partridge using either MAT or IH and both in some instances (Table 6). The isolates from tree hyrax, monitor lizard and civet cat were not characterised because of contamination of their samples.

\section{Discussion}

This study revealed a high prevalence of leptospirosis in wild animals in the study area (78.1\%) compared with other studies elsewhere (Millan et al. 2009; Shearer et al. 2014). It also showed the endemicity of the infection in wild animals in Abeokuta, Nigeria, and possibly in the southwest zone of the country. Factors responsible for this high prevalence are unknown, but it is possible to speculate that climatic conditions such as extended periods of rainfall and flooding, 
elevated temperatures throughout the year and high humidity favoured the prevalence of Leptospira in the study area.

During the last decade in Nigeria, undocumented cases of canine leptospirosis in dogs have been observed in various clinics and post-mortem examinations. Recently, serovars such as icterohaemorrhagiae, pomona, canicola, bratislava and gripptotyphosa have been serologically detected in dogs by Okewole and Ayoola, (2009) in Southwest Nigeria. In this study, these serovars were isolated and identified and possibly showed that wildlife might have been a source of infection to domestic animals.

There seemed to be no significant difference in the prevalence of infection with respect to sex in this study. This agrees with the studies of Hathaway, Blackmore and Marshall (1981) who observed no significant difference between male and female wildlife in their study.

Age-related occurrence of leptospirosis in the animals under investigation appears to be significant. The medium and large animals showed more prevalence than the small size. This might have been because of the fact that as the animal advances in age, the more the chances of exposure to the Leptospira infection. This is in agreement with the works of Hathaway et al. (1981) who observed marked differences in the age-specific prevalence of infection in adult animals in the wild.

Serology has been extensively used in the diagnosis of leptospirosis in the wild (Khan et al. 1991). However, there have been few studies on isolation, characterisation and pathology (Durfee et al. 1977). In this study, isolation and characterisation of Leptospira isolates were performed to ascertain the prevalent serovars. Of the 28 isolates for MAT, $16(57 \%)$ isolates were characterised, while $12(43 \%)$ were not. Serovars such as gripptotyphosa $(n=5)$, hardjo $(n=4)$, icterohaemorrhagiae $(n=3)$, pomona $(n=2)$, bratislava $(n=1)$ and canicola $(n=1)$ were identified in this study. This is in agreement with the earlier study of Okewole and Ayoola (2009) in which these serovars were identified serologically. The 12 unidentified isolates show that there are other serovars in wildlife in Nigeria apart from those recognised. Molecular characterisation of these isolates is underway and might likely show other unknown serotypes that were not previously documented.

The higher number of GCR in this study is in agreement with the works of Okarfor et al. (2013) who affirmed that GCR constitutes about $40.0 \%$ of mammalian species in the study area and their hunting rate is higher during the dry season compared with the rainy season. Of the 16 characterised isolates, GCR had the highest prevalence $(31.3 \%)$ of isolates with five different serovars. The source and high rate of infection in GCR might be attributed to the nature of their ecosystem, since they live in an environment that enhanced the epidemiology of the Leptospira organism, such as marshy areas, river and lake banks (Adeyeye, Olaofe \& Ogunjana 2012; Oboegbulem \& Okoronkwo 1990). Moreover, GCR might possibly be a potential source of infection to other wild and domestic animals (especially cattle and dogs in peri-urban areas) and ultimately, a potential public health hazard to humans that consume smoked and inadequately cooked infected GCR.

Reports on isolation, characterisation and immunohistochemical detection of pathogenic leptospires in antelope are very rare in the literature, although serological evidence of $L$. hardjo has been demonstrated in $3.6 \%$ of 544 antelopes in Colorado, USA (Collins et al. 1981). In this report, of the 22 samples from antelope examined culturally and 6 isolates characterised with MAT, $18(81.8 \%)$ and 4 $(66.7 \%)$, respectively, were positive, while $7(36.8 \%)$ and 2 $(66.7 \%)$ were positive of 19 and 3 samples examined with WSss and IH, respectively. In this study, serovars hardjo, pomona and gripptotyphosa were the most prevalent serovars in this specie.

Studies on isolation and characterisation of pathogenic Leptospira from hare are also rare in the literature. In the work of Hathaway et al. (1981), five hares were examined serologically and culturally, but none of them were positive. In this study, 11 kidneys of hares were examined culturally and $7(71 \%)$ were positive and 3 different serovars were detected immunohistochemically.

Although the numbers of civet cat, pythons, partridge, monitor lizard and bushbuck examined in this study were few, the $100 \%$ positivity shows that larger population of these animals might have been infected with leptospirosis. This might pose a serious concern for the conservation of these animal species in the wild.

The gross and histopathological changes observed in this study were consistent with those observed in domestic animals with renal Leptospira infection (Prescott et al. 2002). Previous studies have associated IN with leptospirosis in the literature (Rossetti et al. 2004; Scanziani, Sironi \& Mandelli 1989; Sterling \& Thiermann 1981; Yener \& Keles 2001). In this study, of the 105 tissues examined histopathologically, IN was observed in $41.0 \%$ and the likely aetiology (leptospires) was present in $78.0 \%$ with CI and $67.7 \%$ using WSss. This possibly showed a positive correlation between IN and the presence of the organism in the renal tissues. The absence of IN in the kidney tissues that were positive to Leptospira organism might be because of the fact that the animals had overcome the infection and the inflammatory response had faded away with time, or that the little portion of the kidney examined might be devoid of such lesions as suggested by Ross et al. (2011). Interstitial fibrosis might have been because of previous subsiding inflammatory lesions induced by Leptospira organism and subsequent scarification.

On tubular colonisation, this study is in agreement with the report by Twigg and Cox (1976) in which PCT, DCT and 
collecting duct were consecutively colonised, but the number of animals involved in their study and the zonal localisation of Leptospira colonies in the renal parenchyma were not documented.

The use of diagnostic methods such as characterisation of leptospiral isolates using mAbs, WSss and $\mathrm{IH}$ is rare in the literature (Wild et al. 2002). To the best of our knowledge, the use of CI, characterisation, WSss, and IH have not been used to diagnose leptospirosis in wild animals in Africa and very few studies have been reported in other parts of the world (Cameron et al. 2008).

The high prevalence of leptospirosis $(78.1 \%)$ in this study showed the endemicity of the infection in the wild. This prevalence might increase in the nearest future because of genetic mutation of the present serovars and possibly as a result of change in climatic conditions such as increase in daily temperature and longer period of rainy season. Thus, contact of wildlife with domestic animals should be prevented, especially in GCR domestication. Vaccination of domestic animals should be encouraged as part of preventive measures with a polyvalent vaccine that contain all identified serovars to provide full coverage. Future studies on the molecular characterisation of all the isolates in this study are warranted. This might detect and elucidate previously unrecognised pathogenic Leptospira organisms as well as the unidentified isolates in this study.

In conclusion, the high prevalence of leptospirosis in this study showed the endemicity of the disease in the wild and might be a potential source of infection to domestic animals and humans. Both gross and histopathological changes showed that wild animals are susceptible to leptospirosis and might be a potential source of infection to both domestic animals and humans. The study also illustrates the necessity of combining of different diagnostic methods in the confirmation of Leptospira infection. Serovars gripptotyphosa and hardjo had the highest prevalence in GCR and antelope, respectively, while serovars bratislava, canicola, icterohaemorrhagiae, pomona and gripptotyphosa were also detected using MAT and $\mathrm{IH}$.

\section{Acknowledgements Competing interests}

The authors declare that they have no financial or personal relationships that may have inappropriately influenced them in writing this article.

\section{Authors' contributions}

O.L.A. and R.E.A. were project leaders and project designers; O.E.O., a microbiologist, contributed to Leptospira isolation; O.G.O. was responsible for sample collection; L.A.O. provided geographical information and contributed to manuscript write up; and O.J.A. performed statistical analysis and contributed to manuscript write up.

\section{References}

Adekunle, M.F. \& Agbaje, B.M., 2011, 'Public willingness to pay for ecosystem service functions of a peri-urban forest in Abeokuta, Ogun State, Nigeria', Proceedings of the Environmental Management Conference, Federal University of Agriculture, Abeokuta, Nigeria, 2012, viewed n.d., from http://www.unaab.edu.ng

Adesiyun, A.A., Hull-Jackson, C., Mootoo, N., Halsall, S., Bennett, R., Clarke, N.R. et al., 2006, 'Sero-epidemiology of canine leptospirosis in Trinidad: Serovars, implications for vaccination and public health', Journal of Veterinary Medicine B 53, 91-99. https://doi.org/10.1111/j.1439-0450.2006.00922.x

Adeyeye, E.I., Olaofe, O. \& Ogunjana, K.E., 2012, 'Lipid profiles of the skin, muscle and liver of greater cane rat (Thryonomys swinderianus): Dietary implication', Elixir Food Science 53, 11749-11756.

Agunloye, C.A., 2002, 'Leptospiral agglutinating antibodies in sheep and goats in southwest Nigeria', PhD thesis, University of Ibadan, Ibadan, Nigeria.

Alton, G.D., Berke, O., Reid-Smith, R., Ojkic, D. \& Prescott, J.F., 2009, 'Increase in seroprevalence of canine leptospirosis and its risk factors, Ontario 1998-2006', Canadian Journal of Veterinary Research 73(3), 167-175.

Boqvist, S., Bergstrom, K. \& Magnusson, U., 2012, 'Prevalence of antibody to six Leptospira servovars in Swedish Wild Boars', Journal of Wildlife Diseases 48(2), 492-496. https://doi.org/10.7589/0090-3558-48.2.492

Cameron, C.E., Zuerner, R.L., Raverty, S., Colegrove, K.M., Norman, S.A., Lambourn, D.M. et al., 2008, 'Detection of pathogenic Leptospira of bacteria in Pinniped populations via $\mathrm{PCR}$ and identification of a source of transmission for zoonotic leptospirosis in the marine environment', Journal of Clinical Microbiology 46(5), 1728-1733. https://doi.org/10.1128/JCM.02022-07

Chin, J. (ed.), 2000, Leptospirosis: Manual of control for communicable diseases, American Public Health Association, Washington, DC, pp. 293-296.

Cirone, S.M., Riemann, H.P., Ruppaner, R., Behymer, D.E. \& Franti, C.E. 1978 'Evaluation of the hemagglutination test for epidemiologic studies of leptospiral antibodies in wild mammals', Journal of Wildlife Diseases 14, 193-202. https:// doi.org/10.7589/0090-3558-14.2.193

Collins, M.T., Gallegos, T.A., Reif, J.S. \& Adrian, W.T., 1981, 'Sero-epidemiology of Leptospira interrogans serovar hardjo in Colorado antelope and cattle', Journal of American Veterinary Medical Association 179(11), 1136-1139.

Cox, T.E., Smythe, L.D. \& Leung, L.K.P. 2005, 'Flying foxes as carriers of pathogenic Leptospira species', Journal Wildlife Disease 41(4), 753-757. https://doi. org/10.7589/0090-3558-41.4.753

Diallo, A.A. \& Dennis, S.M., 1982, 'Bacteriological survey of leptospirosis in Zaria, Nigeria', Tropical Geographical Medicine 34(1), 29-34.

Durfee, P.T. \& Presidente, P.J.A., 1977, 'Isolation of Leptospira interrogans serotype balcanica from a brush-tailed possum (Trichosurus vulpecula)', Australian Veterinary Journal 53, 508. https://doi.org/10.1111/j.1751-0813.1977.tb05485.x

Ellinghausen, H.C., Jr. \& McCullough, W.G., 1965, 'Nutrition of Leptospira pomona and growth of 13 other serotypes: Fractionation of oleic albumin complex (OAC) and a medium of bovine albumin and polysorbate $80^{\prime}$, American Journal of Veterinary Research 26, 45-51.

Everard, C.O.R., Fraser-Chanpong, G.M., Bhagwandin, L.J., Race, M.W. \& James, A.C 1983, Leptospires in wildlife from Trinidad and Grenada, Journal of Wildlife Diseases 19(3), 192-199. https://doi.org/10.7589/0090-3558-19.3.192

Ezeh, A.O., Adesiyun, A.A., Addo, P.B., Ellis, W.A., Makinde, A.A. \& Bello, C.S., 1991 'Serological and cultural examination for human leptospirosis in Plateau State, Nigeria', Central African Journal of Medicine 37(1), 11-15.

Ezeh, A.O., Kmety, E., Ellis, W.A. \& Addo, P.B., 1990, 'A new leptospiral serovar in the Pyrogenes serogroup isolated in Nigeria', Scientific and Technical Review of the Office International des Epizooties 9(4), 1195-1196. https://doi.org/10.20506/ rst.9.4.534

Felt, S.A., Wasfy, M.O., El-Tras, W.F., Samir, A., Rahaman, B.A., Boshra, M. et al., 2011, 'Cross-species surveillance of Leptospira in domestic and peri-domestic animals in Mahalla City, Gharbeya governorate, Egypt', American Journal of Tropical Medicine Hygiene 84(3), 420-425. https://doi.org/10.4269/ajtmh.2011.10-0393

Hamir, A.N., Hanlon, C.A., Niezgoda, M. \& Rupprecht, C.E., 2001, 'The prevalence of interstitial nephritis and leptospirosis in 283 raccoons (Procyon lotor) from 5 different sites in the United states', Canadian Veterinary Journal 42, 869-871.

Hathaway, S.C., Blackmore, W.D.K. \& Marshall, R.B., 1981, 'Leptospirosis in free-living species in New Zealand', Journal of Wildlife Diseases 17(4), 489-496. https://doi. org/10.7589/0090-3558-17.4.489

Johnson, R. \& Harris, V.G., 1967, 'Differentiation of pathogenic leptospires', Journal of Bacteriology 94, 27-31.

Khan, M.A., Goyal, S.M., Diesch, S.L., Mech, L.D. \& Fritts, S.H., 1991, 'Seroepidemiology of leptospirosis in Minnesota wolves', Journal of Wildlife Diseases 27, 248-253. https://doi.org/10.7589/0090-3558-27.2.248

Millan, J., Candela, M.G., Lopez-Bao, J.V., Pereira, M., Jimenez, M.A. \& Leon-Vizcaino, L., 2009, 'Leptospirosis in wild and domestic carnivores in natural areas in Andalusia, Spain', Vector Born Zoonotic Disease 9, 549-554. https://doi. org/10.1089/vbz.2008.0081

Montagnaro, S., Sasso, S., De Martina, L., Longo, M., lovane, V., Ghiurmino, G. et al., 2010, 'Prevalence of antibodies to selected viral and bacterial pathogens in wild boar (Sus scrofa) in Campania Region, Italy', Journal of Wildlife Diseases 46, 316-319. https://doi.org/10.7589/0090-3558-46.1.316

Oboegbulem, S.I. \& Okoronkwo, I., 1990, 'Salmonellae in the African Great Cane Rat (Thryonomys swinderianus)', Journal of Wildlife Diseases 26(1), 119-121. https:// doi.org/10.7589/0090-3558-26.1.119 
Obregón, A.M., Fernández, D.C., Rodríguezy, L.I. \& Rodríguez, T.J., 2007, 'The application of monoclonal antibody methodology as a tool for serotyping application of monoclonal antibody methodology as a tool for serotypir
Leptospira isolates in Cuba', Revista Cubana Medicina Tropica 59(1), 68-70.

Okarfor, K.A., Okete, J.A., Eleng, I.E. \& Odaibo, A.B., 2013, 'Seasonal variations in the mean body weight, length and capture rate of cane rats (Thryonomys swinderianus) in Ibadan, Oyo State, Nigeria', European Journal of Experimental Biology 3(3), 301-306.

Okewole, E.A. \& Ayoola, M.O., 2009, 'Seroprevalence of leptospiral serovars other than Canicola and Icterohaemorrhagiae in dogs in the southwestern Nigeria', Veterinarski Arhiv 79(1), 87-96.

Prescott, J.F., McEwen, B., Taylor, J., Woods, J.P., Abrams-Ogg, A. \& Wilcock, B., 2002 'Resurgence of leptospirosis in dogs in Ontario: Recent findings', Canadian Veterinary Journal 43, 955-961.

Ross, L., Jakowski, R., Bolin, C. \& Kiupel, M., 2011, 'Retrospective immunohistochemical detection of Leptospira in dogs with renal pathology', International Journal of Applied Research in Veterinary Medicine 9(4), 324-331.

Rossetti, C.A., Vanasco, B.N., Pini, N. \& Carfagnini, J.C., 2004, 'Comparison of three diagnostic techniques for the detection of leptospires in the kidneys of wild house mice (Mus musculus)', Revista Pesquisa Veterinária Brasileira 24(1), 6-10. https:// doi.org/10.1590/s0100-736×2004000100003

Scanziani, E., Sironi, G. \& Mandelli, G., 1989, 'Immunoperoxidase studies on leptospiral nephritis of swine', Veterinary Pathology 26, 442-444.
Senthil, K., Ramadass, P. \& Nachimutu, K., 2001, 'Use of polymerase chain reaction for the detection of the leptospires in clinical samples', Indian Veterinary Journal 78 , 1087-1090.

Shearer, K.E., Harte, M.J., Ojkic, D., Delay, J. \& Campbell, D., 2014, 'Detection of Leptospira spp. in wildlife reservoir hosts in Ontario through comparison of immunohistochemical and polymerase chain reaction genotyping methods', Canadian Veterinary Journal 55(3), 240-248.

Sterling, C.R. \& Thiermann, A.B., 1981, 'Urban rats as chronic carriers of leptospirosis: An ultrastructural investigation', Veterinary Pathology 18, 628-637.

Twigg, G.I. \& Cox, P.J., 1976, 'The distribution of leptospires in the kidney tubules of some British wild mammals', Journal of Wildlife Diseases 12, 318-321. https://doi. org/10.7589/0090-3558-12.3.318

Yener, Z. \& Keles, H., 2001, 'Immunoperoxidase and histopathological examinations of leptospiral nephritis in cattle', Journal of Veterinary Medicine A 48, 441-447.

Wild, C.J., Greenlee, J.J., Bolin, C.A., Barnett, J.K., Haake, D.A. \& Cheville, N.E., 2002 An improved immunohistochemical diagnostic technique for canine leptospirosis using antileptospiral antibodies on renal tissue', Journal of Veterinary Diagnostic Investigation 14(1), 20-24. https://dol.org/10.1177, 63870201400105

World Health Organization, 1999, 'Leptospirosis worldwide, 1999,' Weekly Epidemiology Record 74, 237-242. 